\title{
Circulating Endothelial Cells and Vasculitis
}

\author{
Marion HAUBITZ and Alexander WoywodT
}

\begin{abstract}
Systemic vasculitides are a heterogeneous group of disorders with inflammation of blood vessels as their common pathogenetic hallmark. They often pose difficulties with regard to diagnosis and monitoring of disease activity, both at the initial presentation and during follow-up. Novel markers of disease activity are therefore eagerly awaited. Circulating endothelial cells have recently emerged as one such marker and we have demonstrated their clinical use in ANCA-associated small-vessel vasculitis. Not only entire cells but also endothelial microparticles can be detected in vasculitis although their use is not established to date. Repair of endothelial damage is believed to occur via endothelial progenitor cells and their precise role in vasculitis is also unclear at present. Circulating endothelial cells may complement, rather than replace, conventional markers of disease activity. The ultimate aim of our studies may thus be a panel of various laboratory markers for systemic vasculitis.
\end{abstract}

(Internal Medicine 43: 660-667, 2004)

Key words: vasculitis, endothelial cells, endothelial microparticles, endothelial progenitor cells

\section{Introduction}

Vasculitis was recognized as a clinical entity some 150 years ago. Adolf Kussmaul and Rudolf Maier gave the first complete description of systemic necrotizing vasculitis in 1866 and coined the term "periarteritis nodosa". Since then, a variety of vasculitic syndromes have been described, and different terminology has been applied. It was the merit of the Chapel Hill classification (1) to provide a unifying definition of these diseases. Accordingly, vasculitides are now grouped as to the size of the affected vessels. A subgroup of small-vessel vasculitides, which had been identified earlier based on a common histopathology, received particular attention with the discovery of antineutrophil cytoplasmic autoantibodies (ANCA) in 1982 (2). This observation seemed to provide both a laboratory marker of a subgroup of vasculitic syndromes and a new pathogenetic concept (3). However, the use of ANCA as a marker of the disease and its activity has been hampered by a number of limitations, not least the occurrence of high ANCA titers with no disease activity and the fact that ANCA may be detected in nonvasculitic disorders, such as endocarditis (4) or tuberculosis (5). Novel markers are therefore eagerly awaited. Soluble markers, such as plasma von Willebrand factor or thrombomodulin have been evaluated but they, too, have limitations and neither has received much use to date. Circulating endothelial cells have been used as markers in a variety of vascular disorders (6) and we have recently demonstrated their use in ANCA-associated small-vessel vasculitis (7). Here, we describe the isolation of circulating endothelial cells and their use in vascular disorders and especially in systemic vasculitis. We speculate on the pathophysiology of circulating endothelial cells and discuss endothelial repair as well as the possible relevance of endothelial progenitor cells in vasculitis.

\section{Circulating Endothelial Cells: Methods of Isolation}

The concept of circulating endothelial cells is not new. Indeed these cells were first isolated in the 1970s, albeit with non-specific methodology. In particular, detection rested upon the presumed morphology of these cells as seen in smears of peripheral blood $(8,9)$. The next achievement in terms of methodology was to employ immunocytochemistry of peripheral blood smears as demonstrated in sickle-cell anaemia (10). Immunomagnetic isolation has recently appeared as an alternative. Briefly, endothelial cells are isolated from whole blood with magnetic particles (Dynabeads ${ }^{\mathrm{TM}}$, Fig. 1) coated with anti-endothelial antibodies. Depending on the antibody-coating, Dynabeads ${ }^{\mathrm{TM}}$ may be used for isolation of target cells (positive isolation) or depletion of unwanted cells (negative isolation). Figure 2 displays the principle of the technique. The anti-CD 146 antibody (Biocytex, Marseille, France) is widely used for this purpose. With the exception of some tumour cell lines and megakaryocytes, CD146 is a

From the Division of Nephrology, Department of Medicine, Hannover Medical School, Hannover, Germany

Reprint requests should addressed to Dr. Marion Haubitz, Division of Nephrology, Department of Medicine, Hannover Medical School, Carl-NeubergStrasse 1, 30625 Hannover, Germany 


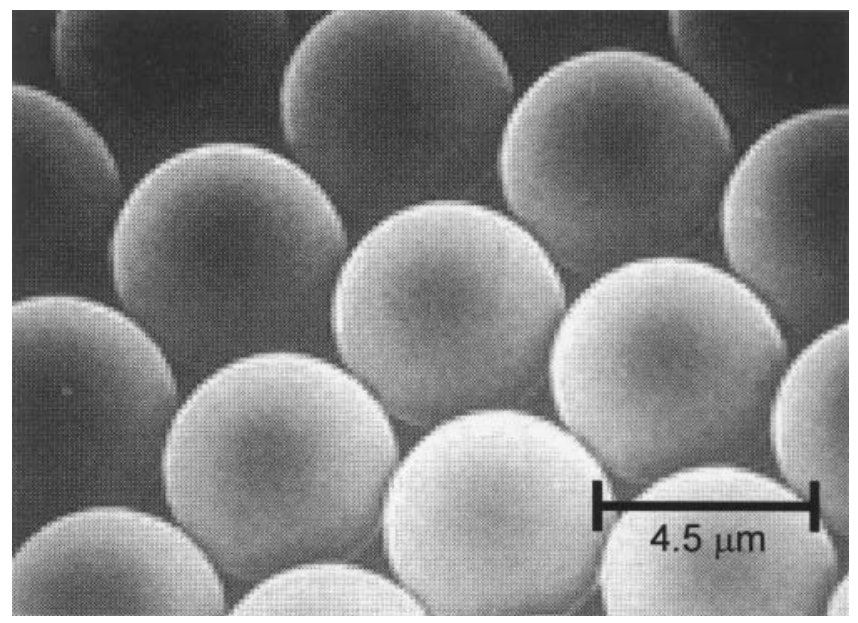

A

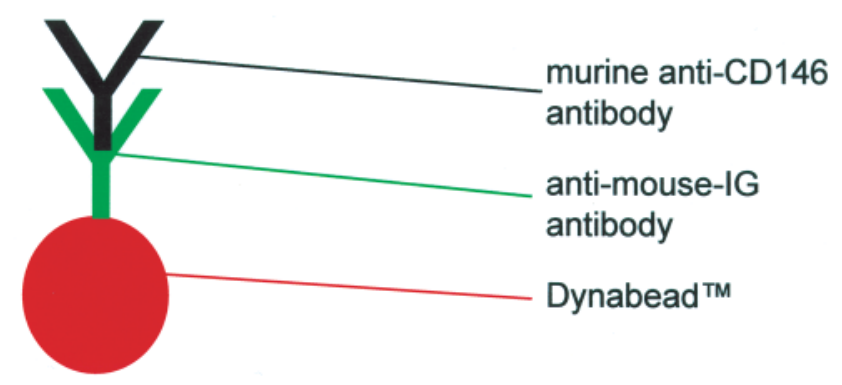

B

Figure 1. Dynabeads ${ }^{\mathrm{TM}}$; A: scanning electron microscopy. B: antibody-coated Dynabead $^{\mathrm{TM}}$.

specific marker of endothelial cells (11). The protein is intimately involved in cell-cell cohesion (12) and cytoskeleton rearrangement (13). Concern has been voiced that endothelial progenitor cells (EPCs) may also express CD146 (14). In our experience, however, cells isolated by anti-CD146dependent immunomagnetic isolation were found to be AC133 negative, thus arguing against a progenitor phenotype. Similarly, it has been argued that CD146-dependent immunomagnetic isolation may also yield pericytes although there is little, if any, data on CD146 expression by these cells. In our experience, staining of cells isolated by CD146 with alpha-smooth-muscle-actin, a typical marker of pericytes, was also negative. In summary, we believe that neither progenitor cells nor pericytes are isolated by CD146dependent immunomagnetic isolation.

There are, however, pitfalls in the technique. One major problem is the non-specific binding of leukocytes to beads. We evaluated the effects of various changes in the technique by pursuing several approaches. For example, M-450 pan mouse IgG Dynabeads ${ }^{\mathrm{TM}}$ without anti-CD 146 antibody were used as controls. It turned out that several factors are sufficient to eliminate non-specific binding, which is believed to occur, at least in part, by means of the Fc receptor. First, Fc receptor blocking agents or incubation with polyclonal immunoglobulins is effective. Temperature is also an issue and working strictly at $4{ }^{\circ} \mathrm{C}$ is essential. Finally, non-specific binding of cells to leukocytes is unstable, while specific, antibody-mediated binding to endothelial cells is not. Therefore, vigorous flushing with the pipette serves to further reduce non-specific binding. To ensure adequate sensitivity, recovery was studied with human umbilical vein endothelial cells. In our hands, recovery was well in excess of $90 \%$ in the range of cell numbers expected in biological specimens, i.e. $10-1,000$ cells $/ \mathrm{ml}$.

Another caveat is the technique of venipuncture. In our experience, the first specimen needs to be discarded to avoid contamination by endothelial cells, which might have been dislodged by the butterfly needle.

After immunomagnetic isolation, enumeration of isolated cells by acridine staining remains the standard but necessitates considerable experience. A simpler test would therefore be of great utility. We have studied the use of immunomagnetic isolation and a variety of subsequent stains, such as CD 31 and von Willebrand factor immunocytochemistry and lectin stains using Ulex Europaeus lectin 1 (UEA-1). Eventually, we devised a simple protocol for immunomagnetic isolation with subsequent UEA-1 lectin stain (15) (Fig. 3).

With regard to their phenotype, circulating endothelial cells may differ depending on the type of underlying disorder (6). Sheets of intact cells have been isolated in patients with acute coronary syndromes whereas severely damaged and necrotic cells were detected in rickettsial infection and vasculitis. Entire cells are usually in the range of 10-50-70 $\mu \mathrm{m}$ but larger aggregates of cells are also seen. Giant cells have been reported in cytomegalovirus infection (16). Smaller endothelial microparticles, which appear to reflect disruption of cells in situ or after detachment from the basement membrane (17), are discussed below.

\section{Circulating Endothelial Cells in Vascular Disorders}

As of today, a broad variety of vascular disorders have been investigated. Both acute and chronic disorders have been studied. In coronary artery disease, circulating endothelial cells were detected in patients with acute myocardial infarction and unstable angina (18). These findings were well in line with current concepts of plaque vulnerability, and patients with stable angina did not exhibit elevated cell numbers. The transplant field offers another exciting opportunity to study vascular disease. For instance, it is well known that renal transplant recipients have a high incidence of vascular complications. We were able to demonstrate elevated numbers of circulating endothelial cells in renal transplant recipients (19). Patients who receive cyclosporine A as part of their immunosuppressive regimen have higher cell numbers than renal transplant recipients who do not receive this drug (20). These findings lend further support to the hypothesis 


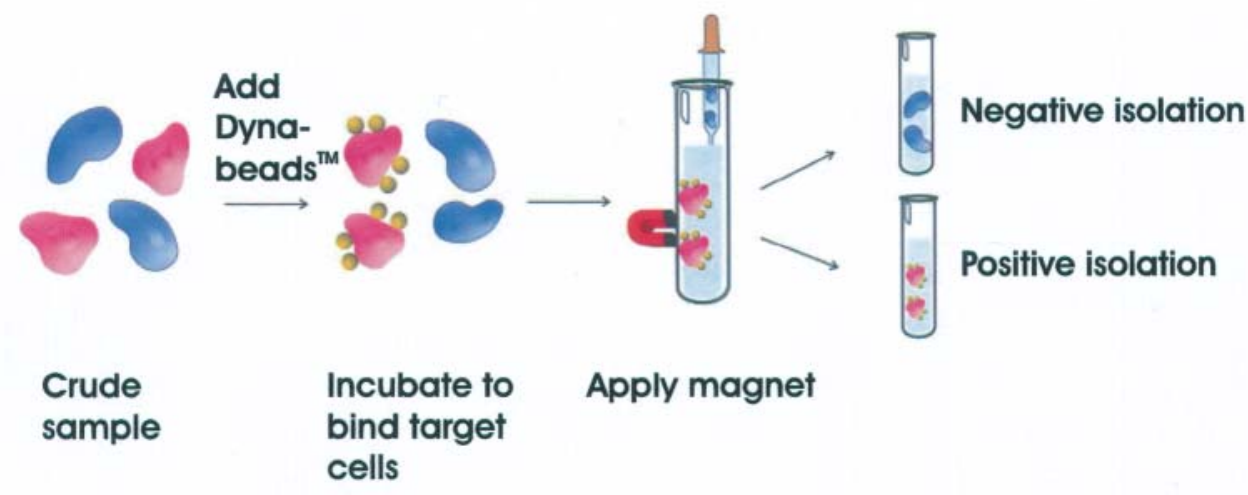

A

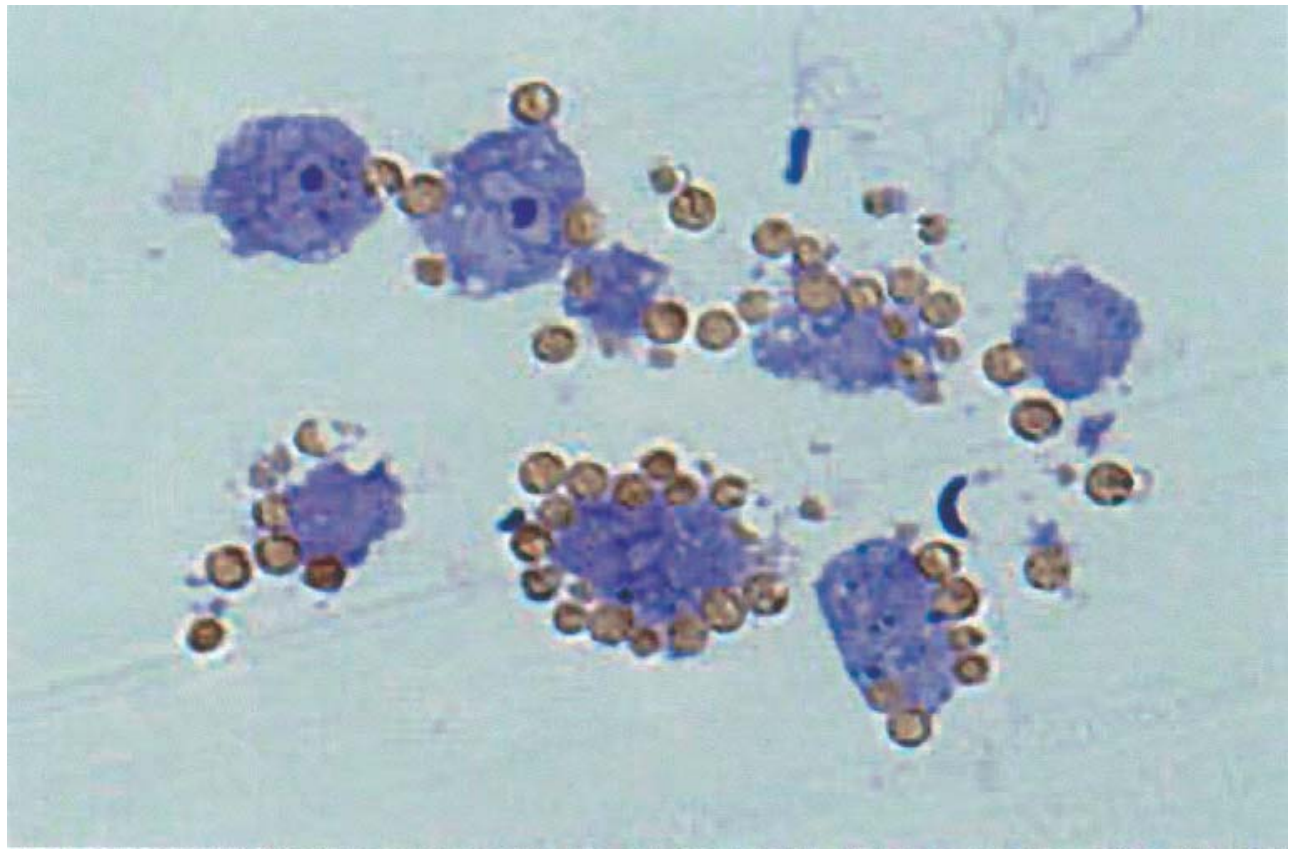

B

Figure 2. Principles of immunomagnetic isolation. A: Positive and negative isolation. B: human umbilical vein endothelial cells isolated from blood by immunomagnetic isolation; note that numerous Dynabeads ${ }^{\mathrm{TM}}$ are attached to the cells.

that calcineurin inhibitors damage microvascular endothelial cells. It remains to be shown whether other transplant recipients and patients on tacrolimus, another calcineurin inhibitor, also have elevated cell numbers. Moreover, studies in patients who receive calcineurin inhibitors for indications other than transplantation as well as monitoring of cell numbers before and after stoppage of such drugs would be worthwhile.

Beyond the enumeration of cells, pathogenetic clues have also been provided by further studies of circulating endothelial cells. In rickettsiosis, Rickettsia conorii was demonstrated within cells that had been retrieved by immunomagnetic isolation $(21,22)$. Likewise, viral antigens were detected on the surface of circulating endothelial cells in cytomegalovirus (CMV) infection $(16,23)$.

In conclusion, where studied, numbers of circulating endothelial cells were indicative of, and correlated with, the degree of endothelial injury. In selected disorders, such as viral or rickettsial infection, phenotypic analysis also provided clues as to diagnosis or pathogenesis.

\section{Circulating Endothelial Cells in Vasculitis}

Damage to microvascular endothelial cells is the hallmark of small-vessel vasculitis. Based on the histology, however, an intriguing question has long been unanswered: Given that 


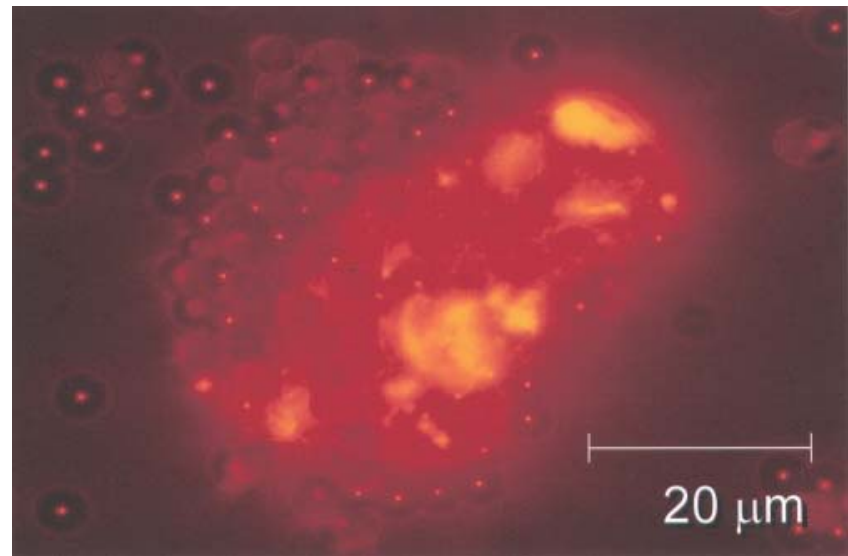

Figure 3. Circulating endothelial cell; immunomagnetic isolation with anti-CD 146-coated beads and subsequent staining with UEA-1.

cells undergo detachment from the basement (Fig. 4), what happens to these cells and can we detect them in peripheral blood? Moreover, it seemed reasonable to assume that the number of circulating endothelial cells would reflect disease extent and activity. For this reason, we became interested in circulating endothelial cells as a possible marker of disease activity in ANCA-associated vasculitis. In our study (7), high numbers of cells $(>100 / \mathrm{ml})$ were detected in patients with active systemic vasculitis; cell numbers declined progressively during the course of successful immunosuppres- sive treatment (Fig. 5). Moderately elevated numbers of circulating endothelial cells were detected in blood obtained from patients in remission. Finally, controls with infection and non-vasculitic renal disease did not have elevated cell numbers. Therefore, the positive predictive value of a cell count above 25 cells $/ \mathrm{ml}$ was $100 \%$ while the negative predictive value was $97 \%$. We concluded that circulating endothelial cells are new markers of ANCA-associated vasculitis, and may be markers of vasculitis in general.

Interestingly, a necrotic phenotype as evidence of the severity of the inflammatory process and tissue-factor expression of the cells could be demonstrated. This finding supports the notion that tissue factor (24) may be an important link between inflammation and coagulation. Tissuefactor positive endothelial microparticles have also been described in sickle cell anemia (25) and in vitro (26). Induction of tissue factor by ANCA and by proteases released during leukocyte activation in ANCA-associated vasculitis has been demonstrated in vitro $(27,28)$. Fibrin, a typical feature of vasculitis lesions, induces tissue factor in endothelial cells (29) while tissue factor, in turn, induces fibrin deposition (30).

One limitation of our study (7) was that only patients with ANCA-associated small-vessel vasculitis had been included. In contrast, data regarding other forms of vasculitis are sparse at present. Dang and co-workers demonstrated elevated numbers of circulating endothelial cells as well as enhanced levels of endothelin in large-vessel vasculitis (31). Nakatani et al have reported similar findings in Kawasaki's disease (32). In 20 patients they demonstrated elevated num-

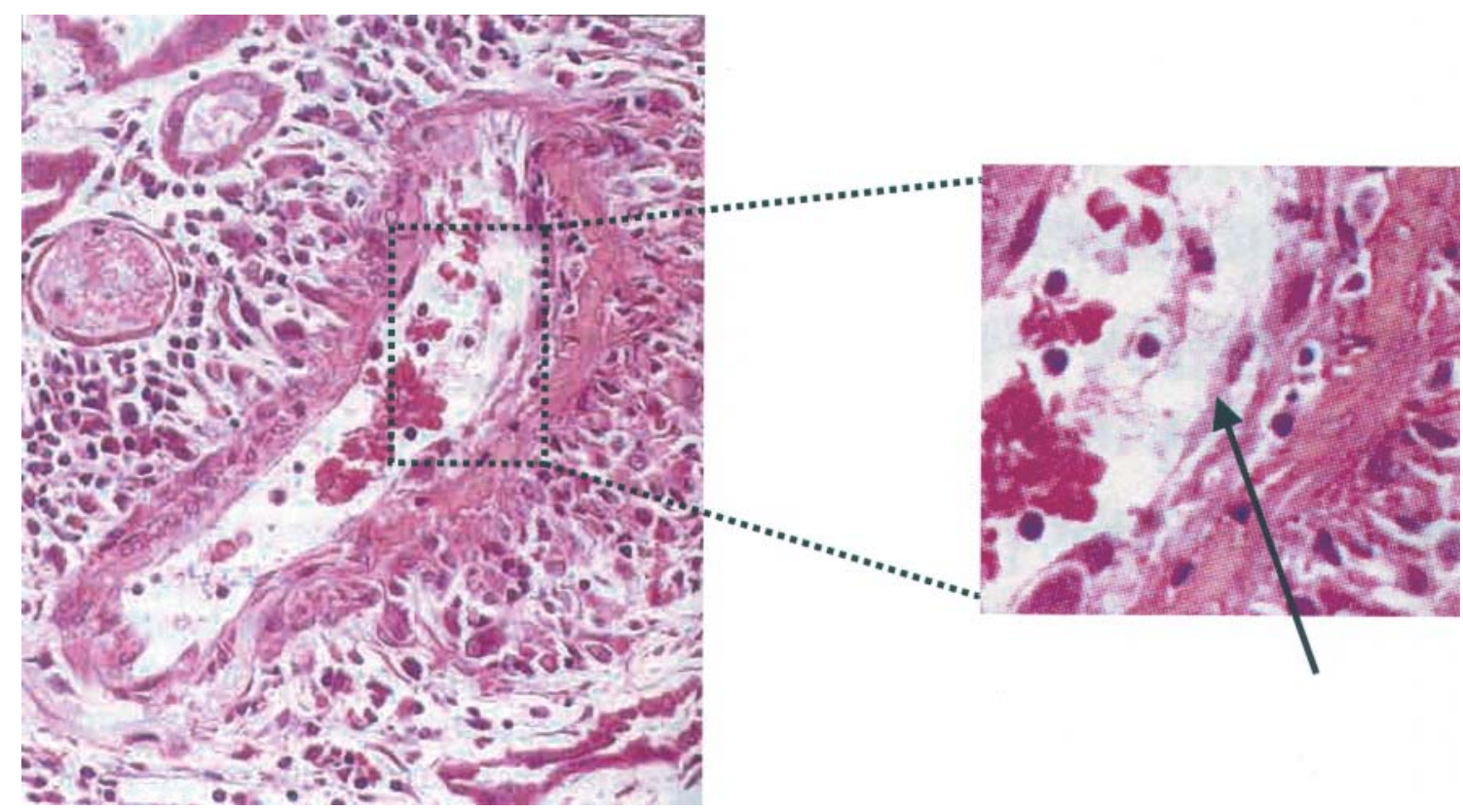

Figure 4. Interlobular artery from a patient with ANCA-associated small-vessel vasculitis. Insert: detachment of an endothelial cell (arrow). Jennette JC, Falk RJ. Renal and Systemic Vasculitis. In: Johnson RJ, Feehally J. Comprehensive Clinical Nephrology. Mosby, London, 2000. 


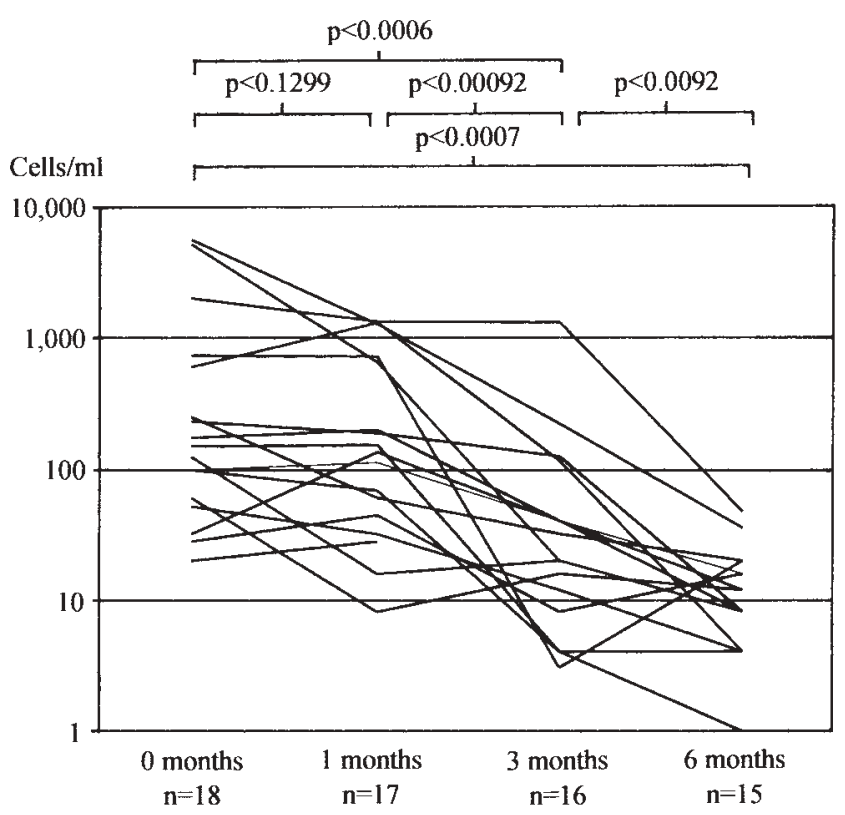

Figure 5. Circulating endothelial cells during the course of treatment in patients with ANCA-associated vasculitis (7).

bers of circulating endothelial cells. Patients with coronary artery lesions had significantly higher cell numbers than patients without lesions, suggesting an association with disease activity.

Another limitation of our study was the lack of patients with relapse. We have meanwhile gathered more experience with the use of this marker in this regard. In our experience, a rise of circulating endothelial cells is observed in patients who relapse although the elevation is rather moderate and protracted (unpublished data). Another application is the use of circulating endothelial cells as a screening test whenever other tests do not suffice. We would like to illustrate this with a case vignette:

A 43-year-old woman with known sarcoidosis was transferred to our intensive care unit with respiratory and renal failure. Sarcoidosis had been diagnosed in 1986 and she was treated with corticosteroids. Following admission elsewhere with bilateral pneumonia, she had quickly deteriorated despite adequate antibiotic treatment. Here, she was in severe respiratory distress with $\mathrm{FiO}_{2} 0.8$ and required high positive end-expiratory pressures. Imaging demonstrated bilateral infiltrates. She remained anuric necessitating continuous venovenous hemodialysis. Vasculitis was not seriously contemplated but a whole set of laboratory markers, including circulating endothelial cells, was requested. Surprisingly, the cell count came back as 92 cells $/ \mathrm{ml}$, which is markedly elevated. ANCA was also measured and MPO-ANCA was positive. Renal biopsy confirmed necrotizing pauci-immune glomerulonephritis and a diagnosis of microscopic polyangitis was made.
As illustrated by the case vignette, we use this marker as an adjunctive tool similar to ANCA measurements. It must be emphasized, however, that both augment rather than replace clinical assessment.

\section{Pathophysiology of Circulating Endothelial Cells}

One enigma about circulating endothelial cells is their way of detachment from the basement membrane. The few data derive from studies into endothelial cell turnover in humans. Labelling studies from the 1980s estimated turnover times from 47 to over 23,000 days (33). Endothelial proliferation is clustered within the vessel and occurs predominantly at sites of branching (34) and turbulent flow. It is well documented that shear stress suppresses endothelial cell apoptosis by virtue of several pathways, such as upregulation of nitric oxide synthase (35). Accordingly, very few circulating endothelial cells are detected in blood obtained from healthy volunteers. Current enumerations are in the range of 5 cells $/ \mathrm{ml}$ blood; however, nothing is known about their phenotype or, for instance, the effect of age and gender. In addition, mechanisms of endothelial detachment in health and disease remain enigmatic.

Another more hypothetic question is whether circulating endothelial cells might be capable of causing an inflammatory response in their own right. Release of substances by circulating necrotic endothelial cells is one pathway by which these cells may exert gain further importance. High mobility group 1 (HMGB1) protein is a protein that is released from necrotic cells. After release, HMGB1 binds to RAGE (the receptor for advanced glycation end products) and acts as a potent mediator of inflammation (36). Other proteins, such as cytochromes, are also released although their significance remains unclear (37). Plasma DNA released from necrotic endothelial cells (38) may also cause secondary phenomena. Finally, release of heat shock proteins from necrotic cells has been shown to deliver a maturition signal to dendritic cells (39). All these proteins may be released from necrotic circulating endothelial cells (Fig. 6) with a whole array of pathophysiological consequences. It must be emphasized, however, that such an assumption is entirely hypothetic at present.

There is another pathway by which necrotic circulating endothelial cells could gain pathophysiological significance. It has been shown previously that cells, such as fibroblasts, are able to sense the presence of necrotic cellular debris in their vicinity (40). This study demonstrated, for the first time, that necrotic but not apoptotic cells initiate a Toll-likereceptor-2/NFkB-dependent reaction in monocytes and fibroblasts. Moreover, the uptake of necrotic cellular material activates macrophages (41). It is conceivable, that healthy endothelial cells or circulating leukocytes react to the presence of necrotic endothelial debris in a very similar manner. 


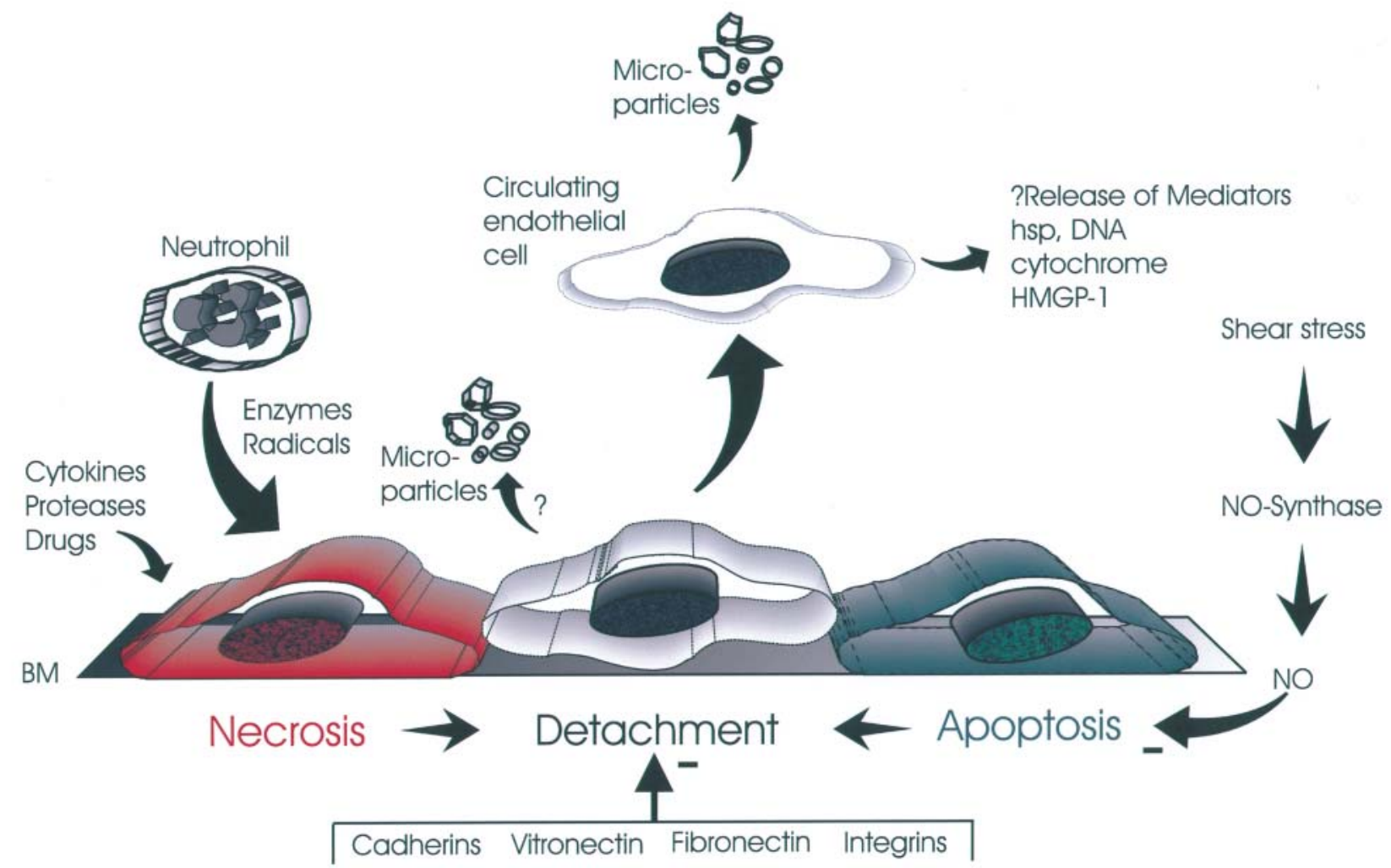

Figure 6. Detachment from the basement membrane; mechanisms and protective factors.

\section{Beyond Entire Cells: Endothelial Microparticles}

Endothelial microparticles have recently emerged as markers of activation in eukaryotic cells. They are usually detected by virtue of annexin staining and size. Resulting from exocytic budding, these vesicles consist of cytoplasmic component and phospholipids. Generation of thrombin by these particles has been demonstrated, suggesting that they are pro-coagulant in vivo (42). It must be emphasized that generation of these particles is not specific to endothelial cells. Instead, microparticles may also derive from platelets and leukocytes. More recently, attempts have been made to isolate microparticles that derive from endothelial cells (43). These particles are capable of inducing a pro-coagulant state (44) and tissue factor has emerged as an important pathway for these events $(25,26)$. Interestingly, we have demonstrated tissue-factor positive circulating endothelial cells in vasculitis (7). These findings suggest that endothelial tissue factor is pivotal as a pro-coagulant mechanism in inflammatory disorders. Taken to the extreme, massive production of microparticles in meningococcal sepsis could well be an important cause of disseminated intravascular coagulation (DIC) (45). Endothelial microparticles have also been detected in patients with acute coronary syndromes. Here, they have been proposed to cause intracoronary thrombi downstream from the vulnerable plaque (46). Endothelial microparticles may also be involved in target-organ damage in severe hypertension (47), diabetes (48) and the procoagulant state in pregnancy (49). Microparticles are only just beginning to be evaluated as a marker in vasculitis. Brogan et al recently gave evidence that endothelial microparticles may help in the diagnosis and monitoring of disease activity in childhood vasculitides (50).

\section{Endothelial Damage: Progenitor Cells for Rescue}

Local proliferation had been regarded as the principal mechanism of endothelial repair until Asahara and colleagues, in 1997, described endothelial progenitor cells (51). These cells are derived from bone marrow and repair defects within the endothelium (52); obviously, transplantation is a promising scenario to study these events: Endothelial cells of donor and recipient origin can be differentiated in female recipients of male grafts. In renal transplant recipients, endothelial chimerism has been demonstrated (53). Moreover, endothelial progenitor cells have been detected in response to myocardial ischemia (54). Recent work has elucidated the effects of drugs, particularly statins and erythropoetin (55- 
57) and the therapeutic use of endothelial progenitor cells is currently under evaluation (58).

In vasculitis, endothelial progenitor cells must be present, given the widespread endothelial damage. The presence of these cells has already been demonstrated in ANCAassociated vasculitis (59) and Kawasaki disease, particularly in patients with complicated coronary artery lesions (32). The number of endothelial progenitor cells increases with delayed kinetics following the increase in circulating endothelial cells, thus suggesting that endothelial progenitor cells are involved in the repair of endothelial damage. It is conceivable that individual susceptibility to vasculitic damage may depend on the ability to mobilize endothelial progenitor cells but this hypothesis needs to be tested. In this regard, the signals that prompt the bone marrow to produce endothelial progenitor cells remain largely unknown. Very recently, erythropoetin has been shown to regulate endothelial progenitor cells (57).

\section{Conclusion}

Circulating endothelial cells are a promising new marker of systemic vasculitis. The clinical use of this marker must now be validated in large numbers of patients. Moreover, the use in vasculitides other than the ANCA-associated forms needs to be established. It is tempting to think about a whole panel of laboratory markers, rather than a single test, to monitor disease activity in systemic vasculitis. This panel may include the ANCA titre and ELISA, circulating endothelial cells, progenitor cells, endothelial microparticles or even novel soluble markers (60). Study of these markers may not only facilitate diagnosis and monitoring but also elucidale the pathogenesis of these disorders. Interactions of circulating endothelial cells and other cells, such as healthy endothelium, remain speculative at present.

\section{References}

1) Jennette JC, Falk RJ, Andrassy K, et al. Nomenclature of systemic vasculitides. Proposal of an international consensus conference. Arthritis Rheum 37: 187-192, 1994.

2) Davies DJ, Moran JE, Niall JF, Ryan GB. Segmental necrotising glomerulonephritis with antineutrophil antibody: possible arbovirus aetiology? Br Med J (Clin. Res. Ed) 285: 606, 1982.

3) Jennette JC, Falk RJ. Small-vessel vasculitis. N Engl J Med 337: 1512 1523, 1997.

4) Choi HK, Lamprecht P, Niles JL, Gross WL, Merkel PA. Subacute bacterial endocarditis with positive cytoplasmic antineutrophil cytoplasmic antibodies and anti-proteinase 3 antibodies. Arthritis Rheum 43: 226-231, 2000.

5) Flores-Suarez LF, Cabiedes J, Villa AR, van der Woude FJ, AlcocerVarela J. Prevalence of antineutrophil cytoplasmic autoantibodies in patients with tuberculosis. Rheumatology (Oxford) 42: 223-229, 2003 (Erratum in: Rheumatology (Oxford) 42: 711, 2003).

6) Dignat-George F, Sampol J. Circulating endothelial cells in vascular disorders: new insights into an old concept. Eur J Haematol 65: 215$220,2000$.

7) Woywodt A, Streiber F, de Groot K, Regelsberger H, Haller H, Haubitz M. Circulating endothelial cells as markers for ANCA-associated small-vessel vasculitis. Lancet 361: 206-210, 2003.

8) Bouvier CA, Gaynor E, Cintron JR, Bernhardt B, Spaet T. Circulating endothelium as an indication of vascular injury. Thromb Diath Haemorrh 40: 163, 1970.

9) Hladovec J, Prerovsky I, Stanek V, Fabian J. Circulating endothelial cells in acute myocardial infarction and angina pectoris. Klin Wochenschr 56: 1033-1036, 1978.

10) Solovey A, Lin Y, Browne P, Choong S, Wayner E, Hebbel RP. Circulating activated endothelial cells in sickle cell anemia. N Engl J Med 337: 1584-1590, 1997.

11) Dignat-George FS, J. CD146. Vol. 2003: Protein reviews on the web, 2003.

12) Bardin N, Anfosso F, Masse JM, et al. Identification of CD146 as a component of the endothelial junction involved in the control of cellcell cohesion. Blood 98: 3677-3684, 2001.

13) Anfosso F, Bardin N, Vivier E, Sabatier F, Sampol J, Dignat-George F. Outside-in signaling pathway linked to CD146 engagement in human endothelial cells. J Biol Chem 276: 1564-1569, 2001.

14) Rafii S, Lyden D. Therapeutic stem and progenitor cell transplantation for organ vascularization and regeneration. Nat Med 9: 702-712, 2003.

15) Woywodt A, Goldberg C, Regelsberger H, Haller H, Haubitz M. A novel assay for the enumeration of circulating endothelial cells. Ann Haematol, epos May 28, 2004.

16) Percivalle E, Revello MG, Vago L, Morini F, Gerna G. Circulating endothelial giant cells permissive for human cytomegalovirus (HCMV) are detected in disseminated HCMV infections with organ involvement. J Clin Invest 92: 663-670, 1993.

17) Woywodt A, Bahlmann FH, de Groot K, Haller H, Haubitz M. Circulating endothelial cells: Life, death and detachment of the endothelial cell layer. Nephrol Dial Transplant 17: 1728-1730, 2002.

18) Mutin M, Canavy I, Blann A, Bory M, Sampol J, Dignat-George F. Direct evidence of endothelial injury in acute myocardial infarction and unstable angina by demonstration of circulating endothelial cells. Blood 93: 2951-2958, 1999.

19) Woywodt A, Schröder M, Gwinner W, et al. Elevated numbers of circulating endothelial cells in renal transplant recipients. Transplantation 76: $1-4,2003$.

20) Woywodt A, Schroeder M, Mengel M, et al. Circulating endothelial cells are a novel marker of cyclosporine-induced endothelial damage. Hypertension 41: 720-723, 2003.

21) George F, Brouqui P, Boffa MC, et al. Demonstration of Rickettsia conorii-induced endothelial injury in vivo by measuring circulating endothelial cells, thrombomodulin, and von Willebrand factor in patients with Mediterranean spotted fever. Blood 82: 2109-2116, 1993.

22) Drancourt M, George F, Brouqui P, Sampol J, Raoult D. Diagnosis of Mediterranean spotted fever by indirect immunofluorescence of Rickettsia conorii in circulating endothelial cells isolated with monoclonal antibody-coated immunomagnetic beads. J Infect Dis 166: 660663, 1992.

23) Grefte A, van der Giessen $M$, van Son $W$, The TH. Circulating cytomegalovirus (CMV)-infected endothelial cells in patients with an active CMV infection. J Infect Dis 167: 270-277, 1993.

24) Semeraro N, Colucci M. Tissue factor in health and disease. Thromb Haemost 78: 759-764, 1997.

25) Shet AS, Aras O, Gupta K, et al. Sickle blood contains tissue factorpositive microparticles derived from endothelial cells and monocytes. Blood 102: 2678-2683, 2003.

26) Kagawa $H$, Komiyama $Y$, Nakamura $S$, et al. Expression of functional tissue factor on small vesicles of lipopolysaccharide-stimulated human vascular endothelial cells. Thromb Res 91: 297-304, 1998.

27) de Bandt M, Ollivier V, Meyer O, et al. Induction of interleukin-1 and subsequent tissue factor expression by anti-proteinase 3 antibodies in human umbilical vein endothelial cells. Arthritis Rheum 40: 2030 2038, 1997.

28) Haubitz M, Gerlach M, Kruse HJ, Brunkhorst R. Endothelial tissue factor stimulation by proteinase 3 and elastase. Clin Exp Immunol 126: 584-588, 2001. 


\section{Circulating Endothelial Cells and Vasculitis}

29) Contrino J, Goralnick S, Qi J, Hair G, Rickles FR, Kreutzer DL. Fibrin induction of tissue factor expression in human vascular endothelial cells. Circulation 96: 605-613, 1997.

30) Erlich JH, Holdsworth SR, Tipping PG. Tissue factor initiates glomerular fibrin deposition and promotes major histocompatibility complex class II expression in crescentic glomerulonephritis. Am J Pathol 150: 873-880, 1997.

31) Dang A, Wang B, Li W, et al. Plasma endothelin-1 levels and circulating endothelial cells in patients with aortoarteritis. Hypertens Res 23: 541-544, 2000.

32) Nakatani K, Takeshita S, Tsujimoto H, Kawamura Y, Tokutomi T, Sekine I. Circulating endothelial cells in Kawasaki disease. Clin Exp Immunol 131: 536-540, 2003.

33) Hobson B, Denekamp J. Endothelial proliferation in tumours and normal tissues: continuous labelling studies. Br J Cancer 49: 405-413, 1984.

34) Schwartz SM, Benditt EP. Clustering of replicating cells in aortic endothelium. Proc Natl Acad Sci USA 73: 651-653, 1976.

35) Dimmeler S, Hermann C, Galle J, Zeiher AM. Upregulation of superoxide dismutase and nitric oxide synthase mediates the apoptosissuppressive effects of shear stress on endothelial cells. Arterioscler Thromb Vasc Biol 19: 656-664, 1999.

36) Scaffidi P, Misteli T, Bianchi ME. Release of chromatin protein HMGB1 by necrotic cells triggers inflammation. Nature 418: 191-195, 2002.

37) Jemmerson R, LaPlante B, Treeful A. Release of intact, monomeric cytochrome c from apoptotic and necrotic cells. Cell Death Differ 9: 538-548, 2002.

38) Jahr S, Hentze H, Englisch $\mathrm{S}$, et al. DNA fragments in the blood plasma of cancer patients: quantitations and evidence for their origin from apoptotic and necrotic cells. Cancer Res 61: 1659-1665, 2001.

39) Basu S, Binder RJ, Suto R, Anderson KM, Srivastava PK. Necrotic but not apoptotic cell death releases heat shock proteins, which deliver a partial maturation signal to dendritic cells and activate the NF-kappa B pathway. Int Immunol 12: 1539-1546, 2000.

40) Li M, Carpio DF, Zheng Y, et al. An essential role of the NF-kappa $\mathrm{B} /$ Toll-like receptor pathway in induction of inflammatory and tissuerepair gene expression by necrotic cells. J Immunol 166: 7128-7135, 2001.

41) Barker RN, Erwig LP, Hill KS, Devine A, Pearce WP, Rees AJ. Antigen presentation by macrophages is enhanced by the uptake of necrotic, but not apoptotic, cells. Clin Exp Immunol 127: 220-225, 2002.

42) Bevers EM, Comfurius P, Dekkers DW, Harmsma M, Zwaal RF. Transmembrane phospholipid distribution in blood cells: control mechanisms and pathophysiological significance. Biol Chem 379: 973 986, 1998.

43) Combes V, Simon AC, Grau GE, et al. In vitro generation of endothelial microparticles and possible prothrombotic activity in patients with lupus anticoagulant. J Clin Invest 104: 93-102, 1999.

44) Sabatier F, Roux V, Anfosso F, Camoin L, Sampol J, Dignat-George F. Interaction of endothelial microparticles with monocytic cells in vitro induces tissue factor-dependent procoagulant activity. Blood 99: 39623970, 2002.

45) Nieuwland R, Berckmans RJ, McGregor S, et al. Cellular origin and procoagulant properties of microparticles in meningococcal sepsis. Blood 95: 930-935, 2000.

46) Mallat Z, Benamer H, Hugel B, et al. Elevated levels of shed membrane microparticles with procoagulant potential in the peripheral circulating blood of patients with acute coronary syndromes. Circulation 101: 841-843, 2000.

47) Preston RA, Jy W, Jimenez JJ, et al. Effects of severe hypertension on endothelial and platelet microparticles. Hypertension 41: 211-217, 2003.

48) Sabatier F, Darmon P, Hugel B, et al. Type 1 and type 2 diabetic patients display different patterns of cellular microparticles. Diabetes $\mathbf{5 1}$ $2840-2845,2002$

49) Bretelle F, Sabatier F, Desprez D, et al. Circulating microparticles: a marker of procoagulant state in normal pregnancy and pregnancy complicated by preeclampsia or intrauterine growth restriction. Thromb Haemost 89: 486-492, 2003.

50) Brogan PA, Shah V, Brachet C, Klein N, Dillon MJ. Endothelial microparticles: just blood "dust," or a "must" for the diagnosis and monitoring of disease activity in childhood vasculitides? Cleveland Clinic Journal of Medicine 69: S 21-041, 2002.

51) Asahara T, Murohara T, Sullivan A, et al. Isolation of putative progenitor endothelial cells for angiogenesis. Science 275: 964-967, 1997.

52) Asahara T, Isner JM. Endothelial progenitor cells for vascular regeneration. J Hematother Stem Cell Res 11: 171-178, 2002.

53) Lagaaij EL, Cramer-Knijnenburg GF, van Kemenade FJ, van Es LA, Bruijn JA, van Krieken JH. Endothelial cell chimerism after renal transplantation and vascular rejection. Lancet 357: 33-37, 2001.

54) Shintani S, Murohara T, Ikeda H, et al. Mobilization of endothelial progenitor cells in patients with acute myocardial infarction. Circulation 103: 2776-2779, 2001.

55) Llevadot J, Murasawa S, Kureishi Y, et al. HMG-CoA reductase inhibitor mobilizes bone marrow-derived endothelial progenitor cells. J Clin Invest 108: 399-405, 2001.

56) Dimmeler S, Aicher A, Vasa M, et al. HMG-CoA reductase inhibitors (statins) increase endothelial progenitor cells via the PI 3-kinase/Akt pathway. J Clin Invest 108: 391-397, 2001.

57) Bahlmann FH, De Groot K, Spandau JM, et al. Erythropoietin regulates endothelial progenitor cells. Blood 103: 921-926, 2004.

58) Kaushal S, Amiel GE, Guleserian KJ, et al. Functional small-diameter neovessels created using endothelial progenitor cells expanded ex vivo. Nat Med 7: 1035-1040, 2001.

59) De Groot K, Goldberg C, Woywodt A, et al. Circulating endothelial progenitor cells (EPCs) in patients with ANCA-associated small-vessel vasculitis. World Congress of Nephrology, Berlin, 2003.

60) Bardin N, Moal V, Anfosso F, et al. Soluble CD146, a novel endothelial marker, is increased in physiopathological settings linked to endothelial junctional alteration. Thromb Haemost 90: 915-920, 2003. 